\title{
Safety of media space: legal regulation and the right of access to information
}

\author{
Gulmira Dzhunushalieva ${ }^{1 *}$, Alla Kovaleva ${ }^{2}$, and Begaiym Maksutova ${ }^{3}$ \\ ${ }^{1}$ Kyrgyz-Russian Slavic University, Chui Avenue 44, Bishkek, 720000, Kyrgyz Republic \\ ${ }^{2}$ Altai State University, Lenin Avenue 61, Barnaul, 656049, Russian Federation \\ ${ }^{3}$ Kyrgyz National University, Frunze St. 547, Bishkek, 720033, Kyrgyzstan
}

\begin{abstract}
The introduction of digital technologies into the daily life of citizens and their communication with government agencies changes the quality of the media space. The system of relations for the production and consumption of information is regulated by the regulatory framework of a particular state. However, the high speed of development of Internet sites, new media, and the expanding circle of communication subjects do not allow timely improvement of the mechanisms of legal regulation of the information space without infringing on the constitutional human right of freedom of access information. The issue is also actualized with the activation of protest movements in the post-Soviet republics since information and communication technologies can significantly influence public opinion, protest sentiments, and destabilize public order. The events in Belarus and Kyrgyzstan in 2020 are already almost examples of classical cases of the use of ICT in the social mobilization of the public masses. The offered ways of solving the problem of improving the legal regulation of the media space are to focus on international ratings of freedom of access to information. It is to understand in which positions the work is not carried out at the proper level; close cooperation with public professional communities that respond more quickly to changes in the information space; in social ordering to stimulate the software development for tracking information of subversive and extremist content in social networks and online communities.
\end{abstract}

\section{Introduction}

The media space is an essential part of the social space, the core of which is the mass information. All objects (state institutions, public organizations, social groups and individuals), one way or another connected with the production and consumption of information, are included in this space. It can be said that the media space is a system of relations for the production and consumption of mass information, which must be and is determined by the framework set by the regulatory legal documents of the state.

The media space has undergone significant structural changes with the introduction and diffusion of information and communication technologies. The reasons for the growing importance of the media space in the life of society and the state are related:

- with the virtualization of social processes that have moved to the internet space and create certain difficulties in the normative and legal regulation of information flows;

- with digitalization of the everyday life of society and the activities of government agencies, which already outlines the future contours of relations between the state and society [1]. They even introduced such a term as "government without a state";
- with powerful potential risks and threats to the security and stability of the social order [2], which requires special forms of work with protest movements [3].

\section{Materials and methods}

The authors used general scientific methods (analysis and synthesis).

\section{Results}

To solve the problem of improving the legal regulation of the media space, the following is required: orientation to international ratings of freedom of access to information as a starting point for defining areas of work. It should be based on ethical codes of public professional communities and analytical calculations of electronic programs for tracking information on subversive and extremist content.

The development of social networks [4], a variety of internet sites, new media, in which individuals become independent producers and consumers of content, contribute to the strengthening of civil society institutions. Civil society itself and communication within and beyond acquires new qualities when 
ethnicity, religious and socio-cultural features are no longer a divisive factor. Technologies allow maintaining interpersonal communication with a high degree of interactivity, depending on the individual characteristics of the communicants. At the same time, media communication is aimed at an audience that is segmented according to certain criteria, but basically remains an abstract group of users / recipients.

In modern conditions, identity can no longer be built in the format of Anderson's "imaginary society" [5] on the principles of ethnicity, religion, or language. The individual gets the opportunity to define his own social group or society through the media. While this process is still unfolding, it is not for nothing that the new generations of children are called generations of Zetas and Alphas [6]. Humanity has entered a period of renewal of the cultural code of humanity. We still use the old set of concepts and concepts, but the growing generation of children chooses what and how to watch on the net, they are actively creating new independent content [7]. To reach such an audience, you have to apply completely new cultural, behavioral, and visual approaches [8]. The most common formats are: pranks, challenges, unpacking, sitcoms, streams, etc. Children, transforming old formats, invent new types of content. while playing computer games, they use the let's play format (a game passing is recorded and laid out in a video blog), children vocalize heroes of a video game. It is the second in popularity on Youtube and about a fifth of the entire video stream of the resource. Peer-generated content is the most popular. For example, the song Baby Shark or Minecraft has launched waves of numerous parodies and challenges.

Experts in the field of mediaology have introduced a new term "media ecosystem" [9] into scientific circulation. Experts define it as an interactive and cohesive system, shaped by content, technology, and social context [10].

On the one hand, the ongoing social processes in the media space democratize the communication exchange of information, remove hierarchical obstacles, and increase the effectiveness of many commercial and political projects. However, the technological update of media tools (various social bot programs, the use of marketing strategies in political campaigns, especially electoral ones, the practice of spreading fake news, strategies for social mobilization) has led to the fact that it has become a key element of modern information wars. Society, deeply going into the virtual space, has not yet developed protective mechanisms against alienation from the social environment. This fact actualizes the issues of ethics, morality, mental health (for example, the sorrowful completely not childish game "Blue Whale"), and the improvement of the legal regulation of the media space [11].

Each state develops its own regulations and judicial practice, which correlate with the concept of "digital rights". The main provisions about new digital objects are related to the introduction of digital technologies in society and the state's economic and social spheres. Experts emphasize that the information space carries the potential for criminality, is used for illegal purposes, and "poses a threat to the information security of the state" [12].

Many researchers confirm that the specialty of law enforcement in the case of the introduction of digital technologies requires the use of constructivism and anthropocentrism methodologies, which put the subject of law at the basis of the legal system. According to Vladimir Mironov, electronic culture raises a whole stratum of communicative and psychological problems characterized by a low level of awareness by the subject of the moral consequences of his activity [13]. The modern powerful information flow brings to a surface understanding of reality by an individual, a loss of skills in critical analysis of texts. It builds a favorable environment for manipulating the legal consciousness of the subject of law enforcement.

The digital environment promotes the spread of a new value system, which will inevitably influence the quality and complexity of the interaction between state, law, and society. Digital technologies contribute to the emergence and spread of new ideas, interpretation of old rituals and myths, giving rise to new ones. This process significantly influences the belief system and motivation of the subjects of law enforcement. The legal technique of acceptance of normative legal acts is directed for introducing the activities of the subject of law into rational boundaries, and the law enforcement itself is predictable.

In modern times, the media space provides conditions for the full flow of communication processes in virtual and physical formats. Psychologists paid attention to the fact that the secondary nature of virtual being in relation to the real does not exclude the transfer of the communicative norms and rules of the Internet to the communicative situations of physical reality. Digital technological capabilities allow carrying out systematic, repeated, long-term aggressive actions of a group or individual in pursuit of someone in the virtual space. This fact has not yet obtained an established terminological classification (cyber mobbing, cyberbullying, trolling, flaming, cyber harassment, cyber-stalking, etc.). Typical actions of pursuing a person are the distribution of deliberately false information about him, ridicule, provocation, insult, and intimidation, which can lead to social isolation, the humiliation of the honor and dignity of a person, causing material and physical damage. Digital technologies and the Internet have removed restrictions of a mass audience, increased the speed of distribution of information, and gave access to personal data of users' social network accounts and ensured anonymity for criminals.

In global communication practice, there is the growth of tendency of persecution of public figures who express skepticism about any socio-political processes in the domestic or foreign policy of the state that attracts the greatest interest of the world or national community. The World Press Freedom Index until 2021 notes that “journalism is a vaccine against disinformation" [14]. International ranking statistics indicate that in a number of countries, access to information or its sources is limited because of the health crisis, which prevents the 
investigation and disclosure of sensitive socio-political topics, especially in Asia, the Middle East, and Europe. According to Secretary-General Christophe Deluar of Reporters Sans Frontiers (RSF), journalism faced "... the virality of cross-border disinformation on digital platforms and social media ..." [14]. According to the indicators of restrictions on journalistic activities in 180 countries, the countries of the post-Soviet space give different results: Estonia (15), Latvia (22), Lithuania (28), Georgia (60), Armenia (63), Kyrgyzstan (79), Moldova (89), Ukraine (97), Russia (150), Kazakhstan (155), Uzbekistan (157), Belarus (158), Tajikistan (162), Azerbaijan (167), Turkmenistan (178) [15]. The rating data proves that the problem of access to information and its right use remains a quite problematic field in which various political projects are implemented against the government or political figures.

Network communication determines the format of social and political relations in the digital environment [16], especially those opposed to the current government $[17$, p. 8]. The new realities of modern socio-political life in the context of the use of technologies and Internet resources in many respects require regulation of mass digital communication. The state is quite clearly aware of the political potential of the digital space, therefore, in most countries, regulations governing relations in digital communication touches on the political sphere (punishment for insulting the authorities). Every state is trying to independently resolve issues of control over digital services and platforms, impose restrictions on their activities, and on the possibility of using their services by civil structures and society. Scenarios of digitalization of the socio-political space of the state have a wide range from refusal to regulate the digital space to reduce state control over society (USA) before control over national segments, which should ensure information security and minimize external information interference (Russia, China, Iran). Based on these scenarios, there is the need to control public mass consciousness, control mass behavior and change mass perceptions, which creates threats to the sustainable development of states that can be declared undemocratic and become targets of violent democratization.

The People's Republic of China defined for itself a strategy for the use of modern technologies in the social and political life of its citizens. The "social credit system" [18], being tested, is prepared by the Chinese authorities to introduce it throughout the state. In general form, this system shows an ecosystem of digital data in which information about the behavior of citizens, companies, and government agencies is stored. A high individual rating of a citizen tied to a QR code will open or restrict access to social benefits and benefits. The system itself has not yet obtained a complete form; many positions are still being discussed. Many experts indicate that the approval of the PRC population for the introduction of a social credit system is solely due to the socio-cultural characteristics of the Chinese [19]. It is unlikely that such a large-scale population tracking system can be afforded by any state. Basically, this kind of project is very capital-intensive and requires a loyal attitude towards the authorities on the side of society.
Nevertheless, the states of the post-Soviet space are trying to exercise control over the media space in the context of ensuring information security and tracking protest sentiments.

Today, the question of digital law is being raised, an electronic format of a legal act, which can become an instrument of legal regulation of modern social relations. In fact, we are talking about changing the use of forms of legal techniques. Experts even claim that its implementation will negatively influence the legitimation of law and law enforcement. First, it concerns an important aspect as the problem of the practical implementation of the norms of digital law.

The regulation of legal relations in digital conditions requires the creation of a system for analyzing digital documents, in which certain contradictions and risks can already be predicted. The specific details and mechanisms of influence on the subjects of the information environment acquire particular importance.

The legal norms of the information sphere should take into account the legal essence of information processes and their aspects, in which legal protection represents social importance for an individual, society, and a state. This requires the development of a conceptual apparatus and spheres of their application, classification of offenses in the field of information, signs of offenses that carry a public danger, and a system of evidence reliability [20].

The information space contains a huge number of different services that provide users with their services. However, their legal regulation is carried out within the framework of civil and tax legislation. The rules for using these resources are established by their owners, who indicate their refusal to be responsible for the content of their sites, shifting it to the user. This fact suggests that both the user and the owner (sometimes) are legally weakly protected. Provision of legal guarantees for the protection of the rights of users and owners of information resources is an actual segment of further improvement of legislation. The COVID-19 pandemic has made employees of various structures work remotely, and this fact is another factor that requires legal support in the regulation of labor relations since the modern edition of the labor codes of the postSoviet republics does not allow this.

In European countries, the right to personal data protection is part of the right to private life. Personal privacy, personal life, and social privacy are considered in French legal practice. The information sphere touches on the social private life of an individual, which is presented in social networks. The European Court of Human Rights has included electronic correspondence in the right of any individual to build relationships with others [21]. Directive of the European Parliament and of the Council of the European Union of December 15, 1997, No. 97/66 / EC [22, p. 1-8] (Directive 97/66/EC of the European Parliament and of the Council of 15 December 1997) indicates the obligation "... of the state at the level of national legislation to ensure the confidentiality of communications carried out via a public telecommunications network and public telecommunications services" [Clause 1, Article 5]. 
The media space needs to establish rules of behavior for users and owners of Internet resources, which will allow preserving all the variety of forms of information activity and minimize risks and threats to the security of society and the state.

The fight against terrorist threats that harm the security of states and human rights accompanies geopolitical competition at the global and regional levels. The political leadership of the countries puts protection of information resources, information security forward in the first place. Clash of economic interests, political projects, and territorial claims complicate interstate cooperation and the exchange of informational data. Therefore, the concept of "information war" has received very real content, which is being implemented in many regions of the world as geopolitical projects of domination.

\section{Conclusion}

What are the recommendations for improving the legal regulation of the media space?

The most understandable and natural mechanism is the acceptance of regulations of various types and levels: the requirement for a printed publication, audio, video, or film product to have an information product mark. However, there are a number of other, illegal ways of regulating the situation in the media space, which states often use, but do not advertise:

- direct and indirect funding, direct pressure, threats to deprive financial, political or intellectual support;

- direct and indirect bribery: the inclusion of editors and journalists in prestigious clubs, commissions, providing opportunities for travel abroad, recreation at famous resorts, etc.;

- refusal to provide information or a threat to deprive of the opportunity to receive information, etc.

There are also various international ratings for assessing the freedom of access to information, which have a substantial justification - the presence of a powerful state media sector.

In the states, public bodies are being created to ensure the "civic component" of regulating the activities of the media. They respond more quickly to changes in the production and consumption of information content in the media product market and develop ethical codes of professional activity. Therefore, such public organizations can provide significant assistance in improving the legal regulation of the media sphere.

From our point of view, it would be quite a justified practice to create IT departments working on the development of a software for tracking actual content in social networks and internet messages spreading information about illegal activities. They can be of nondepartmental subordination and work on the terms of social order on projects for collecting data and working off the provisions of regulatory documents to ensure information and public security of the state.

Therefore, the issues of improving the legal regulation of the information sphere, ensuring the information security of society and the state without barriers to the freedom of access to information, are the basic conditions for the life of modern democratic society.

\section{References}

1. G.V. Morozova, D.R. Fatikhova, E.M. Ziiatdinova, Communication Models of Local Self-Government as a Subject of Modern Russian Policy (Based on Local Self-Government Bodies of the Republic of Tatarstan), Bulletin of Volgograd State University. Series 4. History. Regional Studies. International Relationships, 26(2), 246-254 (2021).

2. T.A. Romanova, N.I. Sokolov, Y.Y. Kolotaev, Disinformation (Fake News, Propaganda) as a Threat to Resilience: Approaches Used in the EU and Its Member State Lithuania, Baltic Region, 12(1), 53-67 (2020).

3. M.I. Krishtal, A.V. Shchekoturov, Effective Risk Communication as a Factor in Managing Protests Attitudes in a Local community, Baltic Region, 12(2), 70-83 (2020).

4. O.V. Komarova, A.E. Denisova, A.A. Belan, E.A. Loskutnikov, The Main Directions of Social Media Development, Russian Journal of Economic Theory, 17(2), 497-502 (2020).

5. B. Anderson, Imagined Communities: Reflections on the Origin and Spread of Nationalism, Revised Edition, 256 p. (Verso, London-New York, 2016).

6. A. Andreeva, The Difference of Generations: What Are They - Generation Z and following "Alphas"? Updated 18 June 2021. Retrieved from: https://trends.rbc.ru/trends/futurology/5dfcabbf9a79 47a532b7f9a5

7. V.D. Dunas, S.A. Vartanov, D.Yu. Kulchitskaya, E.A. Salikhova, A.V. Tolokonnikova, Motivation Factors in Media Consumption of "Digital Youth" in Russia: Results of a Pilot Study, Bulletin of Moscow University. Series 10. Journalism, 2, 3-27 (2020).

8. O.T. Gasparian, Culture Code as a Tool for Realization of Selling Intention in Modern Advertisement, World of the Russian Word, 1, 5661 (2016).

9. S.L. Urazova, Media Ecosystem in the Projection of Technological Innovations, Bulletin of RUDN. Series: Literature Studies. Journalism, 24(3), 477485 (2019).

10. I.M. Dzyaloshinsky, M.A. Pilgun, S.G. Davydov, O.S. Logunova, Media Environment Ecology: the Problems of Safety and Rational Using of the Communication Resources, 176 p. (APK \& PPRO, Moscow, 2015).

11. L.A. Bukalerova, A.V. Ostroushko, O. Criez, Crimes Against the Information Security of Minors Committed Through Information and Telecommunication Networks (Including the Internet), Vestnik of Saint Petersburg University. Law, 1, 17-35 (2021). 
12. V.N. Burlakov, L.N. Plotkina, A.S. Shchurova, Restrictions on the Right to Distribute Information on the Internet in Light of Countering the Spread of Drugs, Vestnik of Saint Petersburg University. Law, 3, 550-562 (2020).

13. V. V. Mironov, Transformation of Culture - from Classical to Electronic, in: Philosophy of Artificial Intelligence, Proceedings of the All-Russian Interdisciplinary Conference, pp. 28-36 (MGU Publ., Moscow, 2017).

14. World Press Freedom Index 2021: Journalism is a vaccine against disinformation, blocked in more than 130 countries, Reporters Sans Frontieres. Retrieved from: https://rsf.org/fr/classementmondial-de-la-liberte-de-la-presse-2021-lejournalisme-est-un-vaccin-contre-la

15. World Press Freedom Index 2021. Reporters Sans Frontieres. Retrieved from: https://rsf.org/fr/classement

16. E. Morozova, I. Miroshnichenko, N. Ryabchenko, Frontier of the Network Society, World Economy and International Relations, 60(2), 83-97 (2016). Retrieved from: https://www.imemo.ru/jour/meimo/index.php?page_ $\mathrm{id}=1248 \&$ file $=$ https://www.imemo.ru/files/File/mag a-zines/meimo/02_2016/83-97_Morozova_.pdf

17. S.V. Volodenkov, The Contemporary Political Processes Transformation in the Context of Society
Digitalization: Key Scenarios, Outlines of Global Transformations: Politics, Economics, Law, 13(2), 6-24 (2020). DOI: 10. $23932 / 25$ 42- 0240 -2020 $13-2-1$

18. L. Kovachich, A. Kolesnikov, Digital Authoritarianism With Russian Characteristics? 21.04.2021. Retrieved from: https://carnegie.ru/2021/04/21/digitalauthoritarianism-with-russian-characteristics-pub84346

19. T. Sysoev, Digital Karma: How China's Social Credit System Will Work. 08.07.2021. RBC. Retrieved from: https://trends.rbc.ru/trends/social/60e5ca569a7947a0 0440ba11исоев

20. D. A. Pashentsev, Features of Law Enforcement in the Conditions of Digitalization of Social Relations, Vestnik of Saint Petersburg University, Law, 1, 3549 (2020). Retrieved from: https://doi.org/10.21638/spbu14.2020.103.

21. Yu.A. Chernysheva, Human Rights in a Digitalized Society, E-journal "Psychology and Law", 9(4), 92102 (2019).

22. Directive 97/66/EC of the European Parliament and of the Council of 15 December 1997 concerning the processing of personal data and the protection of privacy in the telecommunication sector. OJ. L 24. Vol. 41 (30 January 1998) pp. 1-8. 